\title{
PERAN GANDANG TASA \\ DALAM MEMBANGUN SEMANGAT DAN SUASANA PADA PERTUNJUKAN TABUIK DI PARIAMAN
}

\begin{abstract}
Asril*
ABSTRACT

Performing Tabuik in society Pariaman, West Sumatra, is a tradition of cultural influence of Shi'ite Islam that has inherited the local community since about two centuries ago. Tabuik performances are "heroic" and colossal. Pariaman society presented this performance by presenting two Tabuik support group. In certain parts of the performance, these two groups are presented opposite each other. One of the most important elements in each Tabuik performance is gandang tasa, the percussion ensemble. Gandang Tasa role in a variety of contexts and series of performances Tabuik. Gandang tasa most important role is to build the spirit of supporting performances that can trigger mood Tabuik be "hot", especially on hard-dimensional performances, so that it will make a massive fight among the supporters of Tabuik. The method used in this study is a qualitative method that emphasizes the role of the drum in the quality of every part of the Tabuik performance which refers to a variety of atmosphere that was built in the Tabuik perfomance. Gandang Tasa be decisive in establishing the spirit, atmosphere, and the dynamics in each performance of Tabuik.
\end{abstract}

Keywords: tabuik performance, gandang tasa, spirit, the atmospheres of performance

\begin{abstract}
ABSTRAK
Pertunjukan Tabuik dalam masyarakat Pariaman, Sumatra Barat, merupakan tradisi pengaruh budaya Islam Syi'ah yang telah diwarisi masyarakat setempat sejak kurang lebih dua abad yang lalu. Pertunjukan Tabuik bersifat "heroik" dan kolosal. Masyarakat Pariaman mempresentasikan pertunjukan ini dengan menghadirkan dua kelompok pendukung Tabuik. Pada bagian-bagian pertunjukan tertentu, kedua kelompok ini disajikan saling berlawanan. Salah satu unsur terpenting dalam setiap pertunjukan Tabuik adalah gandang tasa, yaitu ansambel musik perkusi. Gandang tasa berperan dalam berbagai suasana dan rangkaian pertunjukan Tabuik. Peran gandang tasa yang terpenting adalah membangun semangat para pendukung pertunjukan Tabuik yang dapat memicu suasana menjadi "panas", khususnya pada upacara yang berdimensi keras, hingga berwujud ke perkelahian massal antarpendukung Tabuik. Metode yang digunakan dalam penelitian ini adalah metode kualitatif yang menekankan kualitas peran gendang di setiap bagian pertunjukan Tabuik yang mengacu pada berbagai suasana yang dibangun dalam pertunjukan Tabuik. Gandang tasa menjadi penentu dalam membangun semangat, suasana, dan dinamika dalam setiap pertunjukan Tabuik.
\end{abstract}

Kata kunci: pertunjukan Tabuik, gandang tasa, semangat, suasana dalam pertunjukan

* Institut Seni Indonesia Padangpanjang, Sumatera Barat 


\section{PENGANTAR}

Musik tradisional dalam budaya Minangkabau terintegrasi dengan berbagai konteks kehidupan yang bersifat sosial, seperti hiburan, seremonial, dan ritual. Bentuk pengintegrasian itu dapat saja bersifat longgar dan bersifat ketat. Bersifat longgar artinya kehadiran musik tidaklah menjadi suatu keharusan dan memberi pengaruh yang sangat penting bagi upacara atau aktivitas yang diikutinya. Di sini musik hanya berperan untuk memeriahkan upacara dan berfungsi untuk hiburan saja. Sementara itu, bentuk pengintegrasian musik yang bersifat ketat berarti kehadiran musik menjadi bagian penting dan berperan menjadi daya hidup bagi upacara atau pertunjukan. Dapat dikatakan juga bahwa upacara sangat bergantung pada kehadiran musik. Kasus seperti ini tidak banyak ditemukan dalam budaya Minangkabau, khususnya setelah masyarakat Minangkabau menyatakan sikap berkeyakinan keagamaan dengan berpedoman kepada adat bersendikan syarak, syarak bersendikan Kitabullah (Adat bersendikan agama Islam dan berpedoman kepada Alquran). Keyakinan-keyakinan yang bersifat mistik pada masa lalu termasuk berbagai ritual yang dianggap dapat merusak aqidah keislaman diperbarui maknanya hingga menjadi aktivitas budaya saja. Sisa-sisa keyakinan masa lalu yang mengalami modifikasi dan dipertahankan hingga sekarang adalah pertunjukan Tabuik di Pariaman yang di dalamnya terintegrasi secara ketat gandang tasa-musik perkusi yang menjadi pendukung pertunjukan.

Pertunjukan Tabuik tidak sepenuhnya adalah budaya Minangkabau, tetapi karena telah hidup dalam kurun waktu yang cukup panjang dalam masyarakat Pariaman, dan telah terjadi pembauran dengan unsur-unsur budaya lokal (Minangkabau) dan keyakinan masyarakat Pariaman yang menganut Islam Sunni, Tabuik dianggap bagian dari budaya Minangkabau khas Pariaman. Pada awalnya pertunjukan ini merupakan ritual keagamaan Islam Syi'ah. Bagi para penganut Syi'ah, ritual ini dirayakan untuk memperingati kematian Husain bin Ali yang meninggal dalam peperangan di Karbala Irak, pada tahun 61 Hijriyah (680 Masehi) (Brockelmann, 1956; Ansary, 2012). Masyarakat Pariaman mempresentasikan peristiwa Husain dengan membentuk dua kelompok pendukung Tabuik, yaitu kelompok pendukung tabuik pasa dan kelompok pendukung tabuik subarang. Kedua kelompok pendukung tabuik itu masingmasing mengusung artefak tabuik sebagai simbol kebesaran dan penghormatan terhadap Husain; dan pada bagian-bagian tertentu dari rangkaian pertunjukan Tabuik dipresentasikan suasana saling berlawanan, dan pada bagian lain melakukan aktivitas pertunjukan secara bersamaan, baik dilakukan di tempat terpisah maupun di suatu lokasi yang sama.

Pelibatan gandang tasa dalam pertunjukan Tabuik berlangsung selama pertunjukan itu dilakukan, yakni antara 10 hingga 14 hari pada awal bulan Muharam. Musik berperan dalam berbagai suasana yang ada dalam pertunjukan Tabuik, seperti gembira, sedih, khidmat, dan khususnya pada suasana berdimensi keras. Di sini, peran musik tampak mendominasi sekali untuk membangkitkan semangat dan amarah para pendukung pertunjukan dalam membangun suasana perlawanan antar kedua pendukung Tabuik. Akan tetapi, suasana menjadi kontras ketika gandang tasa juga diperankan untuk mendukung suasana-suasana yang bersifat sedih dan haru. Seakan-akan ada pemaksaan dalam suasana ini. Dalam budaya musik Minangkabau, sejatinya juga terdapat berbagai genre musik tradisi yang digunakan untuk mendukung suasanasuasana yang bersifat sedih dan haru, seperti musik vokal, gesek, dan tiup, tetapi tidak pernah dimainkan untuk mendukung suasana tersebut. Fenomena ini menjadi alasan penulis untuk mengamati bagaimana kaitan dan peran gandang tasa dalam membangun berbagai suasana dalam pertunjukan Tabuik.

Hingga sekarang dalam setiap pertunjukan Tabuik musik yang digunakan adalah gandang tasa karena perannya dalam membangun berbagai suasana seakan belum tergantikan oleh 
ansambel musik lain. Mengapa begitu penting peran gandang tasa dalam pertunjukan Tabuik? Berdasarkan permasalahan di atas, tujuan penelitian ini adalah untuk mengungkap peran gandang tasa dalam membangun semangat dan berbagai suasana dalam pertunjukan Tabuik.

Penelitian ini adalah penelitian lapangan dengan menggunakan metode kualitatif. Peneliti lebih menekankan pengamatan pada proses dan peristiwa pertunjukan untuk mendukung pembahasan peran gandang tasa dalam setiap suasana dalam pertunjukan Tabuik. Keterlibatan peneliti di lapangan menjadi instrumen penting penelitian ini. Wawancara dengan para pelaku, tokoh/tuo tabuik, dan beberapa tokoh masyarakat, kemudian pendokumentasian peristiwa pertunjukan menjadi bagian yang penting dalam penelitian ini.

Kajian-kajian terdahulu tentang Tabuik telah dilakukan oleh beberapa peneliti. Kajian Tabuik dari perspektif antropologis dilakukan oleh Siregar (1996). Siregar melihat ada tiga unsur terpenting dalam pertunjukan Tabuik, yaitu unsur cerita mitologis, praktik ritual, dan komunitasnya. Tabuik dijadikan cerminan untuk memahami bagaimana masyarakat Pariaman memahami makna ritual Tabuik dan mendayagunakannya sebagai sarana komunikasi simbolik sosio-religius dalam konteks kehidupan masa kini. Yulimarni (2011) melakukan kajian yang memfokuskan pembahasan pada aspek tekstual tabuik dari perspektif ikonografis dan ikonologis. Yulimarni melihat bahwa simbol-simbol yang terdapat pada artefak tabuik merepresentasikan budaya Minangkabau yang berasaskan adat basandi syarak-syarak basandi kitabullah.

Kajian Tabuik dari aspek perubahan dilakukan oleh Rahmanelli (2007) dan Asril (2008). Perubahan yang terjadi pada pertunjukan Tabuik disebabkan oleh aktivitas sosial masyarakat pendukung pertunjukan sebagai tempat perkembangan keruangan dan waktunya yang cenderung progresif dan akibat dari kebijakan pemerintah sehingga Tabuik menyesuaikan dengan irama perkembangan itu.
Tabuik cenderung menampilkan pertunjukan heroik saja. Tabuik yang semula dianggap sakral, kemudian berubah menjurus ke arah atraksi yang bersifat hiburan dan rekreatif. Perubahan juga dikaji pada pelaksanaan Hoyak Tabuik di berbagai kota di luar Pariaman yang sama sekali telah menanggalkan nilai sakral dan tradisi ritus-ritus pertunjukan.

Khanizar (2004, 2005) memfokuskan kajian Tabuik pada aspek estetika postmodernisme. Menurut Khanizar, bentuk konstruksi teks pertunjukan Tabuik merupakan bentuk ketidakmampuan modernisme dalam menanggulangi ketidakpuasan masyarakat yang termarjinalkan. Konsep dekonstruksi postmodernisme yang dibangun dari teks-teks pertunjukan Tabuik membuka pemahaman tidak terbatas pada bentuk, nilai, dan makna saja, tetapi juga membuka interpretasi yang lebih luas.

Ekasari (2011) menelaah kemungkinan Tabuik bisa dijadikan sebagai atraksi pariwisata dalam skala internasional. Ekasari melihat bahwa Tabuik telah terinstitusi secara kuat dalam masyarakat Pariaman. Tiga aspek penting yang ia catat, yaitu (1) aspek sosial, Tabuik menjadi ruang untuk memperkuat hubungan antara individu dalam masyarakat; (2) aspek kultural, Tabuik sudah menjadi tradisi turun-temurun sejak diperkenalkan; dan (3) aspek ekonomi, perayaan Tabuik mampu meningkatkan perekonomian rakyat. Tiga aspek ini sebagai modal yang ditawarkan oleh Ekasari untuk dijadikan sebagai atraksi pariwisata ke level internasional, meskipun beberapa sisi penunjang pariwisata di Kota Pariaman masih jauh dari standar yang diharapkan.

Kajian yang menjurus pada aspek musik (gandang tasa) dalam konteks pertunjukan Tabuik dilakukan oleh Asril (2002, 2005). Menurut Asril faktor penting yang menyebabkan gandang tasa menjadi musik pertunjukan Tabuik adalah aspek instrumen gendang (perkusif); aspek musikal (ritme, tempo, dinamik); latar belakang sejarah Tabuik; situasi total upacara. Meskipun tulisan ini juga sudah membahas hubungan antara ritusritus dalam pertunjukan Tabuik dengan gandang 
tasa, tetapi belum mengupas suasana-suasana yang terdapat dalam pertunjukan Tabuik dan bagaimana peran gandang tasa membangun semangat dan suasana-suasana tersebut. Ruang yang dianggap masih memiliki celah dalam menulis peran gandang tasa dalam pertunjukan Tabuik adalah ambivalensi suasana yang dihadirkan oleh gandang tasa-antara sedih dan gembira disebabkan oleh faktor karakter instrumen perkusi yang lebih cenderung menjadi bersemangat dan gembira.

\section{ANSAMBEL GANDANG TASA}

Masyarakat Pariaman memiliki konsep sendiri tentang musik. Merriam (1968) menjelaskan perlunya memahami pengertian musik atau konsep musik bagi suatu masyarakat. Pengertian musik bagi masyarakat Pariaman tampaknya sama dengan pengertian musik yang berlaku secara universal, yaitu bahwa musik diproduksi melalui vokal dan instrumen. Suara-suara vokal dan instrumen itu kemudian diorganisasikan melalui unsur-unsur musik, seperti melodi, ritme, tempo, harmoni, dan dinamik. Masyarakat Pariaman tidak memiliki konsep khusus tentang musik.

Dewasa ini berbagai jenis musik tradisi dan modern berkembang dalam masyarakat Pariaman. Pada ragam musik tradisi, ditemui ada jenis musik yang hanya memiliki unsur ritme, tempo, dan dinamik saja, dan tidak memiliki unsur melodi. Musik itu adalah gandang tasa. Masyarakat Pariaman tetap menganggap bahwa gandang tasa adalah musik. Alasan mereka cukup kuat karena unsur ritme yang terdapat dalam gandang tasa sudah merupakan unsur pokok dalam musik. Stein (1979) juga menyebutkan bahwa ritme merupakan elemen yang paling dasar dari musik; tanpa ritme musik itu tidak ada.

Bila dilihat dari bentuk orkestrasi atau garapan musik, instrumentasi yang digunakan pada gandang tasa tergolong musik minimalis dan sederhana. Gandang tasa hanyalah sebuah ansambel musik perkusi ritmik yang terdiri atas 6-10 buah gendang bermuka dua (double-headed drum) dan sebuah tasa, jenis gendang bermuka satu (single-headed drum). Lagu-lagu yang dimainkan hanya dibangun dari permainan pola ritme-pola ritme gendang dengan tasa. Tidak ada instrumen yang berfungsi sebagai pembawa melodi, tidak ada gendang yang ditala/distem dengan nada-nada tertentu yang difungsikan sebagai melodi, seperti instrumen taganing (jenis gendang) pada ansambel gondang sabangunan di masyarakat etnik Batak Toba di Sumatra Utara (Purba, 1991; Pasaribu, 1992). Kekuatan musikalnya hanya tertumpu pada permainanpermainan pola ritme. Karakter musiknya bersifat energik, bersuara keras, dan penyajiannya cenderung atraktif sehingga musik ini sangat mendominasi dan menguasai pada prosesi dan lapangan terbuka.

Lagu-lagu yang secara khusus disajikan pada pertunjukan Tabuik adalah Oyak Tabuik, Sosoh, Maatam, dan Katidiang Sompong. Lagu Oyak Tabuik dimainkan pada pertunjukan maoyak tabuik dan menebang batang pisang. Fungsi lagu Oyak Tabuik adalah untuk membangkitkan semangat masing-masing kelompok tabuik (tabuik pasa dan tabuik subarang). Karakter dari lagu ini keras, cepat, energik, dan bersemangat. Kecenderungan yang umum dari setiap penyajian lagu ini adalah pada bagian akhir lagu yang dimainkan lagu Sosoh dengan tempo cepat.

Adapun lagu Sosoh adalah sebuah repertoar pendek yang sejatinya tidak pernah dimainkan secara sendiri. Ia selalu dimainkan bergabung dengan lagu lain, seperti dengan lagu Oyak Tabuik dan Katidiang Sompong. Bahkan, dapat dikatakan lagu Sosoh hanya bagian dari lagu Oyak Tabuik dan Katidiang Sompong, karena lagu Sosoh tidak memiliki pangka matam (semacam pengantar lagu) sebagai bagian dari struktur lagu. Walaupun demikian, lagu Sosoh sangat sering dimainkan dalam pertunjukan Tabuik. Lagu Sosoh dimainkan dalam tempo sedang dan cepat, dan yang paling khas dari lagu ini adalah bertempo cepat. Kata sosoh berasal dari kosa kata Minangkabau yang artinya menyerang saling berhadapan secara frontal. Dalam peperangan atau perkelahian misalnya, sosoh berarti perang terbuka yang saling 
berhadap-hadapan. Peran yang paling utama lagu Sosoh adalah untuk membangkitkan semangat saling memanaskan suasana antara pendukung tabuik pasa dan tabuik subarang.

Lagu Maatam adalah lagu yang disajikan pada saat ritus mengarak jari-jari dalam daraga. (Daraga adalah tempat yang dimitoskan sebagai kuburan atau makam Husain. Daraga berasal dari dargah (Persia) atau durgha (Hindustan) yang berarti pintu atau peti mati (Ronkel 1914; Asril 2002).) Ciri-ciri dari lagu ini bertempo lambat dengan pola ritme sederhana dan dimainkan dengan suara lunak atau lembut. Sementara itu, lagu Katidiang Sompong adalah lagu yang banyak disajikan dalam prosesi untuk membangun suasana pertunjukan agar terasa lebih khidmat. Lagu ini sangat sering dijadikan sebagai bagian awal lagu untuk memunculkan lagu Sosoh.

\section{Gandang Tasa sebagai Musik Pertunjukan Tabuik}

Dalam beberapa penelitian terdahulu (Asril 2002; Muchtar 2005) mencatat aspek-aspek penting keterlibatan gandang tasa sebagai musik pendukung pertunjukan Tabuik antara lain adalah aspek instrumen gendang (perkusif) dan aspek musikal (ritme, tempo, dinamik). Kehadiran gandang tasa sangat diperlukan khususnya pada pertunjukan yang berdimensi keras. Gendang dan tasa dijadikan sebagai stimulus untuk merangsang emosi dan semangat pendukung pertunjukan menjadi "beringas". Ritme-ritme gendang dan tasa yang dimainkan dalam tempo cepat dan dinamik keras akan menghasilkan suara yang "meledakledak" dan akan memicu emosi dan semangat para pendukung pertunjukan. Rodney Needham menjelaskan bahwa gendang memproduksi efek suara yang paling besar sehingga banyak digunakan dalam berbagai upacara (Rouget, 1985). Gendang dalam berbagai bentuk dan ukuran, suara atau bunyinya memiliki efek psikologis dan mampu memengaruhi pendengaran dan syaraf manusia. Kemudian Andrew Neher menyebutkan bahwa gendang dimainkan dengan suara pelan pun dapat mengendalikan getaran, bahkan dapat membuat orang kehilangan kesadaran diri (Rouget, 1985).

Aspek musikal meliputi ritme, tempo, dan dinamik. Suara gendang harus dimainkan dengan ritme. Suara-suara gendang dan tasa diorganisasikan ke dalam berbagai motif dan polaritme sehingga akan mampu memengaruhi dan mengarahkan konsentrasi para pemusik dan pendukung upacara. Motif dan pola ritme yang dimainkan melalui gendang dan tasa akan menjadi lebih efektif dengan memasukkan tempo dan dinamik. Tempo amat diperlukan untuk memperlambat dan mempercepat lagu. Dalam kasus upacara Tabuik, tempo diperlukan khususnya untuk mempercepat lagu. Contohnya, lagu Sosoh yang dimainkan dengan tempo sedang biasanya tidak membuat situasi upacara menjadi 'panas'. Akan tetapi, bila tempo lagu Sosoh itu dipercepat, situasi upacara akan berubah menjadi "panas" atau gembira. Begitu juga, dengan lagu Oyak Tabuik saat disajikan pada upacara maoyak tabuik, perubahan tempo yang cepat akan membuat "irama" upacara manjadi "panas". Perubahan tempo yang menjadi cepat dalam pertunjukan gandang tasa dipicu oleh tasa. Perubahan ini cenderung diikuti pula dengan suara yang keras. Secara tidak langsung, unsur dinamik telah dilibatkan dalam memainkan gendang dan tasa.

Jadi, aspek instrumen (perkusif) dengan suara keras dan kekuatan musikal dengan karakter energik yang dimiliki oleh gandang tasa sangat sulit digantikan oleh ansambel musik tradisi Minangkabau lainnya. Syafruddin Auang, yaitu tuo tabuik subarang (pawang dan pemimpin tabuik subarang), mengatakan bahwa gandang tasa harus ada, bahkan "wajib" hukumnya dalam setiap pertunjukan Tabuik, tanpa peran gandang tasa pertunjukan Tabuik tidak bisa dijalankan (wawancara, 21 November 2012 di Pariaman). Oleh sebab itu, hingga saat ini, para tuo tabuik dan pelaku pertunjukan tidak melihat ada alternatif ansambel musik tradisi Minangkabau lainnya selain gandang tasa yang digunakan sebagai musik dalam pertunjukan Tabuik. 


\section{PERAN GANDANG TASA DALAM PERTUNJUKAN TABUIK}

Pertunjukan Tabuik secara visual diwujudkan dengan dua artefak tabuik setinggi 10 sampai 12 meter. Tabuik pertama disebut dengan tabuik pasa (Pasar Pariaman) dan tabuik kedua disebut dengan tabuik subarang (V Koto Air Pampan). Pertunjukan Tabuik terdiri dari beberapa tahap ritus upacara/pertunjukan, yaitu mengambil tanah, menebang batang pisang, maatam atau mahatam, maradai, mengarak jari-jari, mengarak sorban, tabuik naiak pangkek, ma-oyak tabuik, dan mambuang tabuik. Ritus-ritus itu dapat dikelompokkan atas beberapa suasana, yaitu khidmat, sedih, haru, dan berdimensi keras. Suasana khidmat lebih mengarah pada ritus yang memerlukan kekhusukan dalam melakukannya. Suasana sedih dan haru menggambarkan tragedi dan kedukaan. Adapun suasana yang berdimensi keras adalah sajian-sajian upacara yang menyuguhkan tekanan-tekanan dalam bentuk konfrontatif, seperti perkelahian antarpendukung Tabuik. Selain itu, ada suasana untuk mengundang rasa simpati dan untuk kemeriahan saja.

Suasana khidmat dapat dirasakan pada ritus mengambil tanah. Pertunjukan ini dilakukan di sungai di dua tempat yang berbeda oleh kelompok pendukung tabuik pasa dan tabuik subarang dalam waktu yang bersamaan. Ritual ini menggambarkan pengambilan mayat Husain yang masih tertinggal di Karbala. Lagu yang dimainkan adalah Katidiang Sompong dan Sosoh. Gandang tasa dimainkan sejak dari daraga di masingmasing tempat, sampai ke lokasi pengambilan tanah. Gandang tasa dimainkan sambil berjalan sepanjang 1-1,5 km. Pertunjukan gandang tasa yang sangat penting adalah pada saat mengambil tanah di sungai. Pada saat inilah peran gandang tasa sangat dirasakan untuk membangun suasana kekhidmatan dan kekhusukan.

Hingga menjelang akhir 1990-an, ritual mengambil tanah dilakukan bertepatan dengan kumandang azan magrib di surau dan masjid di sekitar ritual berlangsung. Bersamaan dengan itu, gandang tasa juga dimainkan untuk membangun kekhusukan dan kekhidmatan. Satu sisi, ritual ini telah 'bertabrakan' dengan ritual ibadah Islam: salat magrib. Akan tetapi, sejak 2000an hingga sekarang koreksi dan penyesuaian ritual mengambil tanah dilakukan oleh tuo tabuik (pawang dan pemilik tabuik), yakni pelaksanaan mengambil tanah dilakukan sebelum atau sesudah salat magrib. Jika dilakukan sesudah salat magrib, pada menjelang azan aktivitas ritual dihentikan, dan gandang tasa juga tidak dimainkan lagi.

Suasana haru dan sedih diwujudkan melalui ritus maatam dan ritus mambuang tabuik (tabuik dibuang ke laut). Maatam adalah prosesi mengarak jari-jari dalam daraga. Jarijari yang diarak merupakan penggambaran jari-jari Husain yang terpisah dari tubuhnya akibat dari peperangan di Karbala. Lagu yang dimainkan adalah lagu Maatam dengan suara lunak dan tempo lambat. Maatam artinya nyanyian kesedihan. Para peserta prosesi umumnya terdiri dari ibu-ibu, mereka mengelilingi makam Husain yang terdapat dalam daraga sambil mengucapkan kata-kata: Hosen ... Hosen ... Hosen. Pelafalan kata-kata Hosen sebagai bentuk kedukaan dan rasa sedih terhadap nasib Husain.

Akan tetapi, pengamatan yang dilakukan secara cermat, baik secara langsung maupun melihat kembali rekaman lapangan yang dibuat, tampaknya sangat sulit bagi para peserta prosesi maatam itu mengungkapkan ekspresi kesedihan. Bahkan, mereka cenderung melakukannya sebagai ritual tanpa muatan sakral atau kedalaman rasa dan penghayatan. Lagu Maatam yang dimainkan dengan gandang tasa yang difungsikan untuk membangun suasana duka dan sedih seperti tidak mengantarkan mereka ke suasana yang dimaksudkan dalam ritus itu. Suara dari sejumlah gendang yang rendah (low) yang dimainkan dalam tempo lambat dan pola ritme yang sederhana, pada awalnya mampu mengantarkan peserta prosesi ke suasana sedih. Akan tetapi, situasi terasa menjadi berlawanan ketika suara tasa yang nyaring (bersuara tinggi) dimainkan bersama gendang dengan pola ritme yang berbeda karena suara tasa itu lebih cenderung menjauhkan suasana dari kesedihan. Para peserta prosesi berada pada 
"ruang" suasana ambivalensi antara sedih dan bukan sedih (gembira dan senang). Mereka agak sulit memahami bagaimana menjiwai dan meresapi ritme-ritme dari instrumen musik perkusi (gendang dan tasa) dijadikan sebagai pendukung suasana sedih dan duka.

Ambivalensi seperti dikatakan oleh Bhabha sebagai ruang antara atau ruang ketiga (Ashcroft dkk., 1998) merupakan situasi yang menempatkan subjek tidak berada pada ruang pertama dan juga tidak pada ruang kedua. Ambivalensi juga menjadi terasa lebih kuat lagi karena para pelaku prosesi dan para pemusik adalah masyarakat Pariaman penganut Islam Sunni. Mereka hanya berupaya menginterpretasikan suasana sedih. Jadi, mereka sebenarnya tidak pernah benar-benar merasakan kesedihan seperti yang dirasakan oleh para pelaku ritual mengenang kematian Husain yang dilakukan oleh para penganut Syi'ah di Iran dan beberapa kawasan Asia Selatan dan Timur Tengah.

Di penghujung ritus maatam (masih dalam daraga), tempo musik dipercepat suara gendang dan tasa diperkeras sehingga suasana langsung berubah dari yang dipersepsikan sedih menjadi gembira, bahkan para peserta prosesi mengekspresikan kegembiraan mereka dengan berjoged-joged dan tertawa. Di luar konteks ritus atau pertunjukan maatam pun, lagu Maatam jika dimainkan dengan tempo yang lebih cepat (sedang), ia akan membangun suasana senang atau gembira. Pemicu utamanya tampak dari karakter suara tasa yang nyaring.

Kasus ambivalensi suara musik (gandang tasa) dan antara pemahaman penganut Islam Syi'ah dan Sunni dengan menggunakan instrumen gendang dan tasa (dhol dan tasa) dalam ritus maatam juga ditemui dalam masyarakat Tamil dan beberapa etnis di India Selatan dan Pakistan sebagaimana ditulis oleh Wolf (2000) dalam artikelnya, "Embodiment and Ambivalence: Emotion in South Asian Muharram Drumming". Wolf menyimpulkan bahwa suara tasa dengan frekuensi suara yang tinggi tidak dapat membangun suasana sedih, bahkan cenderung menjadi gembira seperti juga yang terjadi dalam masyarakat Pariaman dalam ritus maatam.

Sebagaimana diiformasikan pada bagian awal tulisan ini, hingga saat ini tidak ada jenis atau ansambel musik Minangkabau lainnya yang digunakan untuk mendukung suasana sedih dan duka atau haru. Berbagai repertoar dendang saluang dan rabab dengan teks sedih dan duka serta ditunjang dengan karakter melodi yang bersifat sedih (melankolis) tidak pernah menjadi alternatif ataupun eksperimentasi digunakan dalam ritus maatam.

Suasana haru terdapat pada ritus mambuang tabuik. Ritual ini merupakan penggambaran jenazah Husain dibawa ke pemakaman. Artefak tabuik diusung bersama-sama ke pinggir pantai Samudra Indonesia pada sore hari, kemudian ditenggelamkan dalam laut. Gandang tasa hanya dimainkan pada bagian awal saja, sebagai pengantar dimulainya ritus mambuang tabuik. Lagu yang dimainkan adalah Katidiang Sompong atau Matam Panjang dan Sosoh. Selanjutnya prosesi ke pantai hingga tabuik ditenggelamkan tidak ada musik dimainkan. Suasana haru seolaholah dibangun oleh keheningan pelaku prosesi dan ribuan pengunjung yang seakan-akan berperan sebagai pelayat mengantar jenazah kepemakaman.

Peran gandang tasa yang sangat menonjol adalah pada pertunjukan yang berdimensi keras, yaitu pada ritus menebang batang pisang, mengarak jari-jari, mengarak sorban, dan maoyak tabuik. Ritus menebang batang pisang merupakan prosesi ritual menebang batang pisang yang dilakukan di dua tempat yang berbeda. Selama perjalanan dari pusat aktivitas tabuik masing-masing hingga ke lokasi penebangan batang pisang, gandang tasa dimainkan untuk menghidupkan suasana. Pertunjukan gandang tasa yang sangat penting adalah pada saat penebangan batang pisang. Gandang tasa berperan sebagai stimulus untuk membangkitkan semangat yang mengarah pada "patriotik" karena pada bagian upacara ini merupakan penggambaran ketajaman pedang Husain menebas atau membunuh musuh pada saat perang. Lagu yang dimainkan adalah lagu Oyak Tabuik dan Sosoh (Asril, 2002). Sajian 
ritme-ritme yang dimainkan melalui gendang dan tasa mampu membuat suasana menjadi tegang dengan emosional yang meletup-letup. Situasi ini digambarkan secara visual dengan munculnya seseorang yang berperan sebagai kesatria menggunakan pedang kemudian menebang batang pisang yang ada di lokasi upacara.

Bagian akhir atau puncak dari ritus ini adalah perkelahian antara pendukung tabuik pasa dan tabuik subarang ketika mereka bertemu di perempatan Tugu Tabuik. Mereka diskenariokan harus melewati perempatan Tugu Tabuik untuk berpapasan atau berselisih. Perempatan Tugu Tabuik disebut juga dengan "Padang Karbala" Pariaman. Ketika kedua rombongan prosesi tabuik sudah berada di areal Tugu Tabuik, masing-masing mereka meningkatkan intensitas permainan gandang tasa untuk membangkitkan semangat dan emosi para pendukung upacara. Lagu Sosoh dalam tempo cepat dan dinamik keras dimainkan berulang-ulang agar akumulasi semangat dan emosional lebih cepat memuncak. Lagu Sosoh merupakan lagu yang khusus dimainkan pada suasana ini. Puncak dari ekspresi emosional kemarahan ini adalah perkelahian antar pendukung tabuik pasa dengan pendukung tabuik subarang. Pada situasi ini, antara emosi musikal dengan emosi (perasaan marah) sudah membaur menjadi satu. Emosi musikal dibangun lewat tempo cepat dan dinamik keras. Emosi dalam musikologi dimaknai sebagai cepat lambat (elemen tempo) atau keras lembutnya (elemen dinamika) sebuah komposisi (Djohan, 2009). Efek dari emosi musikal gandang tasa membias kepada perilaku dan sikap para pendukung upacara.

Pada bagian ini gandang tasa sangat menentukan jalan dan dinamika pertunjukan. Peran gandang tasa terasa amat diperlukan. Intensitas emosi para pendukung upacara atau pertunjukan hanya dapat dibangun melalui gandang tasa. Jika gandang tasa tidak dimainkan oleh kedua pendukung Tabuik, mereka tidak akan melakukan perkelahian atau suasana yang menjurus pada ketegangan.
Sementara itu, ritus maoyak tabuik merupakan puncak dari seluruh rangkaian pertunjukan Tabuik. Maoyak tabuik adalah atraksi dengan artefak tabuik, seperti mengangkat, menggoyang-goyangkan, menghentakkan, memutar, dan membawa berlari, bahkan saling membenturkan antara kedua tabuik. Atraksi ini dilakukan oleh kedua pendukung tabuik dengan cara saling mendesak atau menekan secara bergantian. Selama aktivitas ini berlangsung, gandang tasa dengan lagu Oyak Tabuik dan Sosoh dimainkan dengan tempo cepat dan dinamik keras untuk membangun semangat para pendukung tabuik. Ketegangan suasana terakumulasi oleh semangat yang dibangun oleh gandang tasa, tak jarang juga mengarah pada perkelahian antara kedua pendukung tabuik. Akan tetapi, sepanjang pelaksanaan pertunjukan Tabuik pada ritus maoyak tabuik belum pernah terjadi perkelahian. Puncak letupan kemarahan adalah mengadu tabuik, tetapi sangat jarang dilakukan.

Maoyak tabuik merupakan bagian pertunjukan yang paling banyak mengundang perhatian para pengunjung. Pada tahun 1980-an, selain atraksi dengan tabuik, sindiran-sindiran dalam bentuk sarkasme dan beberapa simbol yang dekat dengan kehidupan masyarakat juga disampaikan untuk mengejek dan membangkitkan amarah pihak lawan masing-masing. Ini merupakan bentuk sajian yang bersifat provokatif. Bagian itu menjadi daya tarik yang menggelikan bagi para pengunjung. Akan tetapi, sejak dua dekade terakhir ini, sudah tidak disajikan lagi. Bahkan, sekarang pun, terjadi pereduksian atraksi maoyak tabuik, dibandingkan dengan dekade sebelumnya.

Ritus yang dianggap berdimensi keras lainnya adalah mengarak jari-jari dan mengarak sorban. Kedua ritus ini merupakan prosesi mengarak bagian dari tubuh dan sorban atau turban Husain yang bercerai berai pada saat peperangan di Karbala. Dua benda ini dijadikan sebagai pengundang simpati dan kemarahan pendukung tabuik. Khusus pada ritus mengarak jari-jari, 
bentuk kemarahan pendukung tabuik bermuara pada perkelahian antara kedua pendukung tabuik. Ini merupakan perkelahian massal yang kedua. Proses dan bentuk perkelahiannya sama dengan yang terjadi pada ritus menebang batang pisang, tetapi luapan kemarahannya bisa berbeda-beda. Jika pada ritus menebang batang pisang terdapat korban luka-luka di salah satu pihak, mereka akan "membalaskan dendamnya" pada ritus mengarak jari-jari. Artinya, suasana bisa bertambah panas. Suasana panas dan perkelahian ini diperkuat dan dipicu oleh gandang tasa dengan lagu Sosoh. Peran gandang tasa pada saat ini adalah untuk membangkitkan semangat para pendukung upacara untuk berkelahi.

Sementara itu, pada ritus mengarak sorban, peran gandang tasa lebih banyak ditujukan untuk menggairahkan suasana prosesi saja. Sangat jarang sekali terjadi perkelahian pada ritus ini, kecuali jika pada perkelahian sebelumnya (mengarak jarijari) terjadi korban luka atau lebih parah di satu pihak, pihak yang korban akan melakukan "balas dendam" pada ritus mengarak sorban. Dalam ungkapan lokal Pariaman hal itu disebut Sabuang salapeh hari patang, Sibungsu indak baradiak lai 'Ini merupakan pertandingan/perkelahian terakhir, tidak ada lagi perkelahian setelah ini'. Untuk mengantisipasi agar situasi tidak menjadi makin "panas" atau bisa menjadi brutal, berbagai pertimbangan dan perundingan dilakukan antara para tuo tabuik, ninik mamak, dan tokoh masyarakat kedua pihak agar perkelahian tidak dilakukan, seperti yang terjadi pada pertunjukan Tabuik tahun 2012. Walaupun demikian, masingmasing pendukung tabuik akan tetap memainkan gandang tasa untuk membangkitkan semangat dan emosi marah mereka. Mereka memainkan gandang tasa di lokasi masing-masing di bawah pengawasan ninik mamak, tuo tabuik, dan tokoh masyarakat hingga para tokoh masyarakat itu menghentikan ritus itu.

Kebiasaan atau tradisi yang terbangun dalam masyarakat Minangkabau secara umum yang juga berlaku di Pariaman adalah membangun dialektika dalam berbagai aspek sosial, terutama yang menyangkut dengan kepentingan kelompok dan masyarakat secara luas. Menurut Zubir (2010), dalam dinamika kehidupan masyarakat Minangkabau, terdapat dua nilai yang kuat memengaruhi tingkah laku dan pemikiran masyarakatnya yaitu adat dan Islam. Kedua nilai itu pada periode tertentu berjalan berdampingan saling mengisi antara nilai-nilai adat dan nilai agama Islam. Namun, sebaliknya pada periode lain, kedua nilai itu sering merupakan sumber konflik yang keras dan berkepanjangan yang menimbulkan berbagai gejolak intelektual dan fisik. Konflik mempunyai kedudukan penting dalam menumbuhkan dinamika kebudayaan. Konflik tidak hanya membawa ke arah perpecahan, sebaliknya inilah yang menjadi sumber dinamika dalam masyarakat di Minangkabau.

Kaitannya dengan pertunjukan Tabuik, tampak bahwa perkelahian sebagai wujud dari konflik, tidak selamanya juga dipandang sebagai tindakan yang bersifat negatif. Dengan memberikan "ruang" untuk berkelahi antarsesama pendukung tabuik pasa dan tabuik subarang, ini dapat dipandang sebagai pelepasan letupan energi emosional selama upacara karena selesai pertunjukan Tabuik, tidak ada balas dendam antara kelompok atau pribadi di luar konteks pertunjukan. Kalau ingin membalaskan dendam, tunggu pada pertunjukan Tabuik tahun berikutnya.

Peran tokoh masyarakat, tokoh adat, alim ulama, dan pemuda dari kedua komunitas tabuik ketika perkelahian berlangsung dilakukan atas izin dan kontrol mereka. Hal ini dapat dipandang bahwa berkelahi dalam konteks pertunjukan Tabuik mendapat legitimasi dari adat dan agama. Berkelahi sebagai wujud konflik menjadi penting dalam menumbuhkan dinamika dalam masyarakat Pariaman. Perkelahian masih dipertahankan hingga sekarang sebagai dinamika pertunjukan Tabuik dan menjadi tontonan bagi masyarakat. Perkelahian yang terjadi sebenarnya bukan perkelahian yang lepas kontrol dan benar-benar kacau, tetapi masih dapat dikelompokkan sebagai perkelahian yang "direkayasa" meskipun terdapat luka atau korban di masing-masing pihak. 
Suasana simpati dibangun melalui ritus maradai. Ritus ini bertujuan mengundang rasa simpati masyarakat untuk menyumbangkan dana atau apa saja untuk membantu pembuatan tabuik. Pada masa pertunjukan Tabuik masih dilaksanakan sepenuhnya oleh anak nagari masyarakat Pasar Pariaman dan V Koto Air Pampan, biaya pembuatan dan pelaksanaan upacara dilakukan secara gotong royong. Peran gandang tasa pada ritus ini hanyalah untuk memeriahkan suasana saja. Begitu juga pada ritus tabuik naiak pangkek, gandang tasa dimainkan agar suasana pada upacara ini terasa lebih meriah. Lagu-lagu yang dimainkan ditujukan hanya untuk menyemangati suasana upacara.

Tabel 1

Peran Lagu pada Ritus-ritus Pertunjukan Tabuik

\begin{tabular}{|c|c|c|c|c|}
\hline Ansambel & Lagu & Ritus & Suasana & Keterangan \\
\hline \multirow{9}{*}{$\begin{array}{c}\text { Gandang } \\
\text { Tasa }\end{array}$} & $\begin{array}{c}\text { Katidiang } \\
\text { Sompong, } \\
\text { Sosoh }\end{array}$ & $\begin{array}{l}\text { Mengambil } \\
\text { tanah }\end{array}$ & khidmat & $\begin{array}{c}\text { Membangun } \\
\text { suasana } \\
\text { khidmat }\end{array}$ \\
\hline & & Mahatam & Sedih & $\begin{array}{l}\text { Suasana sedih } \\
\text { tidak tercapai }\end{array}$ \\
\hline & $\begin{array}{l}\text { (maatam), } \\
\text { Katidiang } \\
\text { Sompong }\end{array}$ & $\begin{array}{l}\text { Mambuang } \\
\text { tabuik/ } \\
\text { tabuik } \\
\text { dibuang ke } \\
\text { laut }\end{array}$ & $\begin{array}{l}\text { Sedih dan } \\
\text { haru }\end{array}$ & $\begin{array}{c}\text { Musik hanya } \\
\text { dimainkan di } \\
\text { bagian awal } \\
\text { saja }\end{array}$ \\
\hline & \multirow{4}{*}{$\begin{array}{c}\text { Oyak } \\
\text { Tabuik, } \\
\text { Katidiang } \\
\text { Sompong, } \\
\text { dan Sosoh }\end{array}$} & $\begin{array}{l}\text { Menebang } \\
\text { Batang } \\
\text { Pisang }\end{array}$ & $\begin{array}{l}\text { Berdimensi } \\
\text { keras }\end{array}$ & $\begin{array}{c}\text { Membangun } \\
\text { semangat dan } \\
\text { emosi;terjadi } \\
\text { perkelahian } \\
\text { antara kedua } \\
\text { pendukung } \\
\text { tabuik }\end{array}$ \\
\hline & & $\begin{array}{c}\text { Maoyak } \\
\text { tabuik }\end{array}$ & $\begin{array}{l}\text { Berdimensi } \\
\text { keras }\end{array}$ & $\begin{array}{l}\text { Membangun } \\
\text { semangat, } \\
\text { saling tekan, } \\
\text { dan dorong }\end{array}$ \\
\hline & & $\begin{array}{c}\text { Mengarak } \\
\text { jari-jari }\end{array}$ & $\begin{array}{l}\text { Berdimensi } \\
\text { keras }\end{array}$ & $\begin{array}{c}\text { Membangun } \\
\text { semangat, } \\
\text { terjadi } \\
\text { perkelahian, } \\
\text { bisa juga tidak }\end{array}$ \\
\hline & & $\begin{array}{l}\text { Mengarak } \\
\text { sorban }\end{array}$ & $\begin{array}{c}\text { Berdimensi } \\
\text { keras/ } \\
\text { khidmat }\end{array}$ & $\begin{array}{l}\text { Tidak terjadi } \\
\text { perkelahian }\end{array}$ \\
\hline & \multirow{2}{*}{$\begin{array}{c}\text { Katidiang } \\
\text { Sompong, } \\
\text { Oyak } \\
\text { Tabuik }\end{array}$} & $\begin{array}{c}\text { Tabuik Naiak } \\
\text { Pangkek }\end{array}$ & Kemeriahan & $\begin{array}{l}\text { Membangun } \\
\text { suasana }\end{array}$ \\
\hline & & Maradai & Simpati & $=$ \\
\hline
\end{tabular}

\section{SIMPULAN}

Warisan dan tradisi yang dijalankan oleh masyarakat Pariaman secara turun temurun telah membuktikan bahwa gandang tasa menjadi musik pendukung pertunjukan Tabuik dan terintegrasi secara ketat. Posisi ini belum tergantikan oleh ansambel musik tradisi Minangkabau lainnya. Gandang tasa berperan dalam membangun semangat dan mendukung berbagai suasana dalam pertunjukan Tabuik, terutama pada ritus atau upacara berdimensi keras. Suara dan ritmeritme yang dilahirkan oleh gendang dan tasa, dan karakter musiknya yang bersifat energik menjadi kekuatan musik ini dalam memicu emosi dan semangat para pendukung pertunjukan. Akan tetapi, tidak semua suasana dalam pertunjukan Tabuik dapat didukung dengan baik oleh gandang tasa. Seperti pada suasana sedih, misalnya, tampak bahwa ada unsur pemaksaan peran gandang tasa. Rasa sedih tidak bisa dibangun oleh gandang tasa, justru kehadirannya menimbulkan ambivalensi bagi para pendukung pertunjukan, yakni berada pada "ruang antara" sedih dan gembira. Rasa sedih tidak terwujud dalam diri para peserta prosesi dan pemusik.

\section{DAFTAR RUJUKAN}

Ansary, Tamim. (2012) Dari Puncak Bagdad: Sejarah Dunia Versi Islam. Jakarta: Zaman.

Ashcroft, Bill., Gareth Griffiths, dan Helen Tiffin. (1998). Post-Colonial Studies: The Key Concepts. London dan New York: Routledge.

Asril. (2002). "Pertunjukan Gandang Tambua dalam Upacara Ritual Tabuik di Pariaman Sumatera Barat". Tesis S2 Universitas Gadjah Mada, Yogyakarta.

- (2008). "Upacara Tabuik dalam Sosial Budaya Masyarakat Pariaman: Keberlangsungan dan Perubahannya". Laporan penelitian, Padangpanjang: STSI Padangpanjang.

Brockelmann, Carl.(1956). History of The Islamic Peoples. Terj. Joel Carmichael dan Moshe Perlmann, London: Routledge and Keagan Paul Ltd.

Djohan. (2009). Psikologi Musik, Cetakan III, Yogyakarta: Best Publisher.

Ekasari, Rini. (2011)."The Culture of West Sumatera and Tourism: Can "Tabuik" Festival in Pariaman Became an International Tourist Attraction?" Tesis 
S2 University of Angers.

Khanizar. (2004). "Dekonstruksi Estetika Postmodernisme: Membaca Wacana Idealitas Estetis Upacara Tabuik di Pariaman Sumatra Barat". Jurnal Bheri Jurnal Ilmiah Musik Nusantara Vol. 3 No.1, hlm. 65-78.

(2005).Upacara Tabuik di Pariaman, Sumatra Barat: Analisis Melalui Teori Dekonstruksi dan Wacana Estetika Postmodernisme. Tesis S2 Universitas Udayana, Denpasar.

Merriam, Alan P. (1968). The Anthropology of Music. Chicago: Northwestern University Press.

Muchtar, Asril. (2005). "Gandang Tambua: Musik Pembangkit Semangat 'Heroik' dan 'Patriotik'. dalam Upacara Tabuik di Pariaman, Sumatra Barat". Jurnal Panggung STSI Bandung, No. XXXVII, hlm. 67-74.

Pasaribu, Ben M. (1992). "Taganing Batak Toba: Suatu Analisis Struktural dan Stratifikasi Sosial" dalam Nugraha, Sugeng (ed.). Seni Pertunjukan Indonesia. Surakarta: Masyarakat seni Pertunjukan Indonesia.

Purba, Mauly. (1991). "Mangindo Gondang di dalam Penyajian Musik Gondang Sabangunan pada Masyarakat Batak Toba". Jurnal Masyarakat Musikologi Indonesia, Tahun II No. 2, hlm. 134163.

Rahmanelli. (2007). "Upacara Ritual Tabuik dalam
Konteks Perubahan Budaya di Kota Pariaman”. Tesis S2 Universitas Negeri, Padang.

Rouget, Gilbert. (1985). Music and Trance: A Theory of the Relations between Music and Possession. Chicago dan London: The University of Chicago Press.

Siregar, Miko. (1996). "Tabuik Piaman Kajian Antropologis terhadap Mitos dan Ritual (Studi Kasus di Pariaman Tengah, Kabupaten Padang Pariaman, Sumatra Barat)". Tesis S2 Universitas Indonesia, Jakarta.

Stein, Leon. (1979). Structure and Style the Study and Analysis of Musical Forms. Princeton, New Jersey: Summary-Bichard Music.

Yulimarni. (2011). "Tabut Subarang Tahun 2010 Dalam Tradisi Muharram Masyarakat Pariaman di Sumatra Barat". Tesis S2 Institut Seni Indonesia, Yogyakarta.

Zubir, Zaiyardam. (2010). Budaya Konflik dan Jaringan Kekerasan: Pendekatan Berdasarkan kearifan Lokal Minangkabau. Yogyakarta: INSISTPress.

Wolf, Richard K. (2000). "Embodiment and Ambivalence: Emotion in South Asian Muharram Drumming". Yearbook for Traditional Music 32:81-116. http://nrs.harvard.edu/urn-3 (diakses 4 February,2014). 


\section{Lampiran}

Lagu Oyak Tabuik dan Sosoh

Transkrip: Asril

Keterangan: $\mathrm{GD}=$ gendang (drum)

Bagian I: Lagu Oyak Tabuik
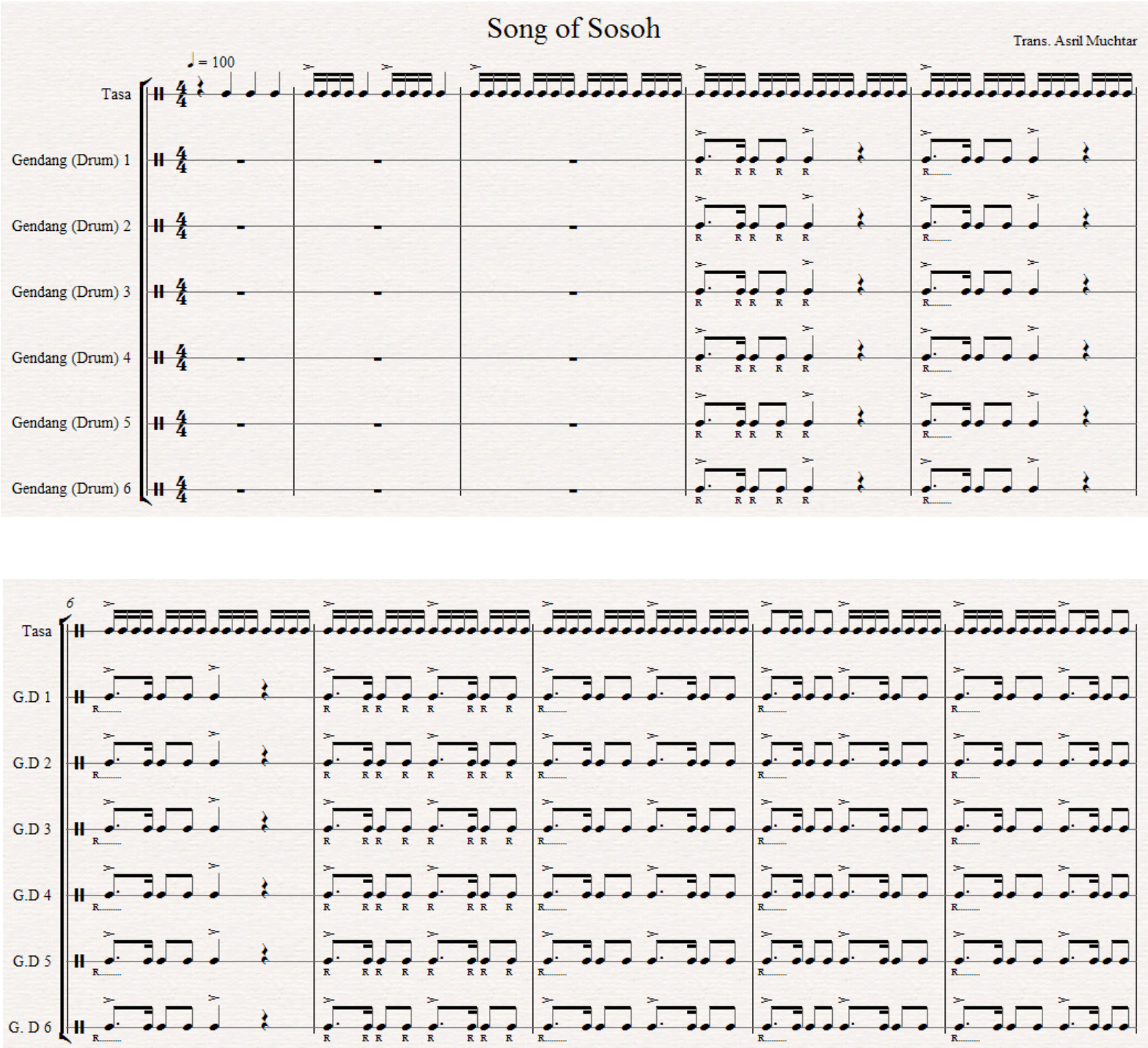


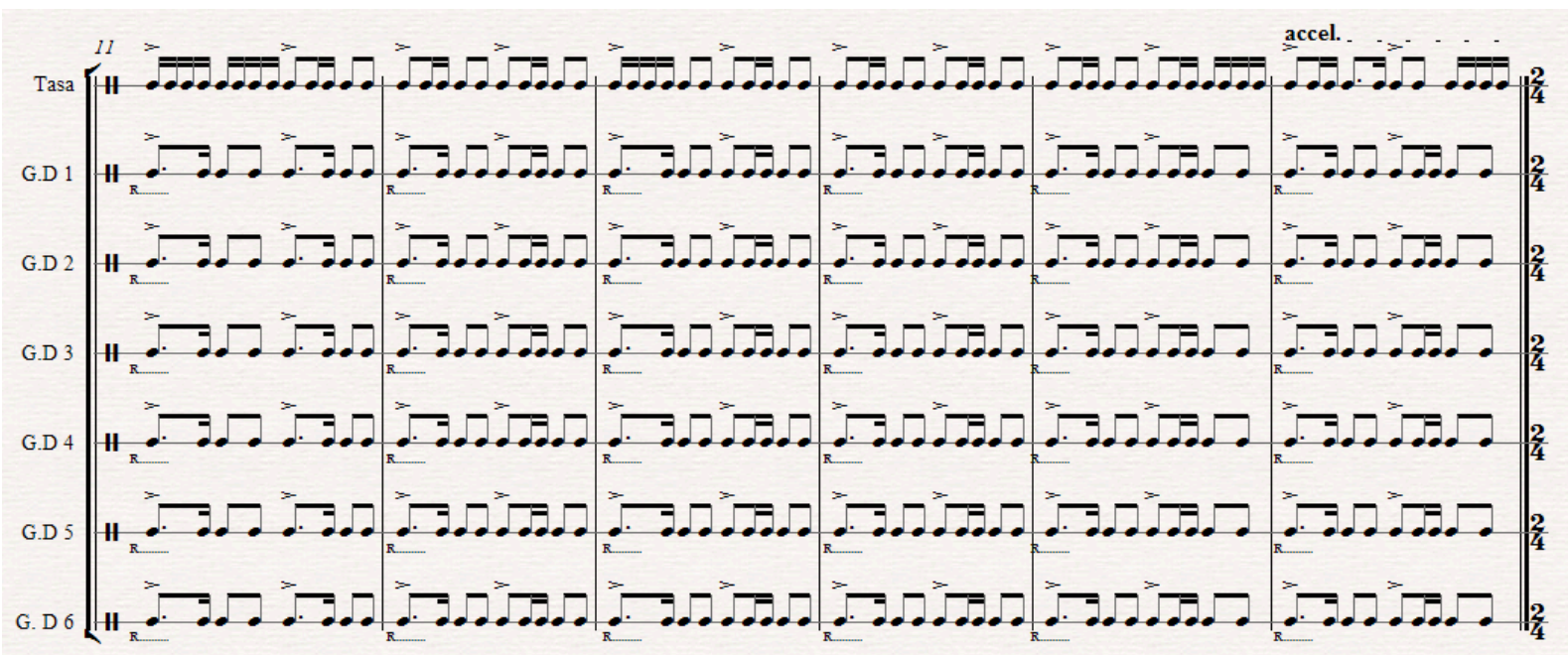

Bagian II: Lagu Sosoh
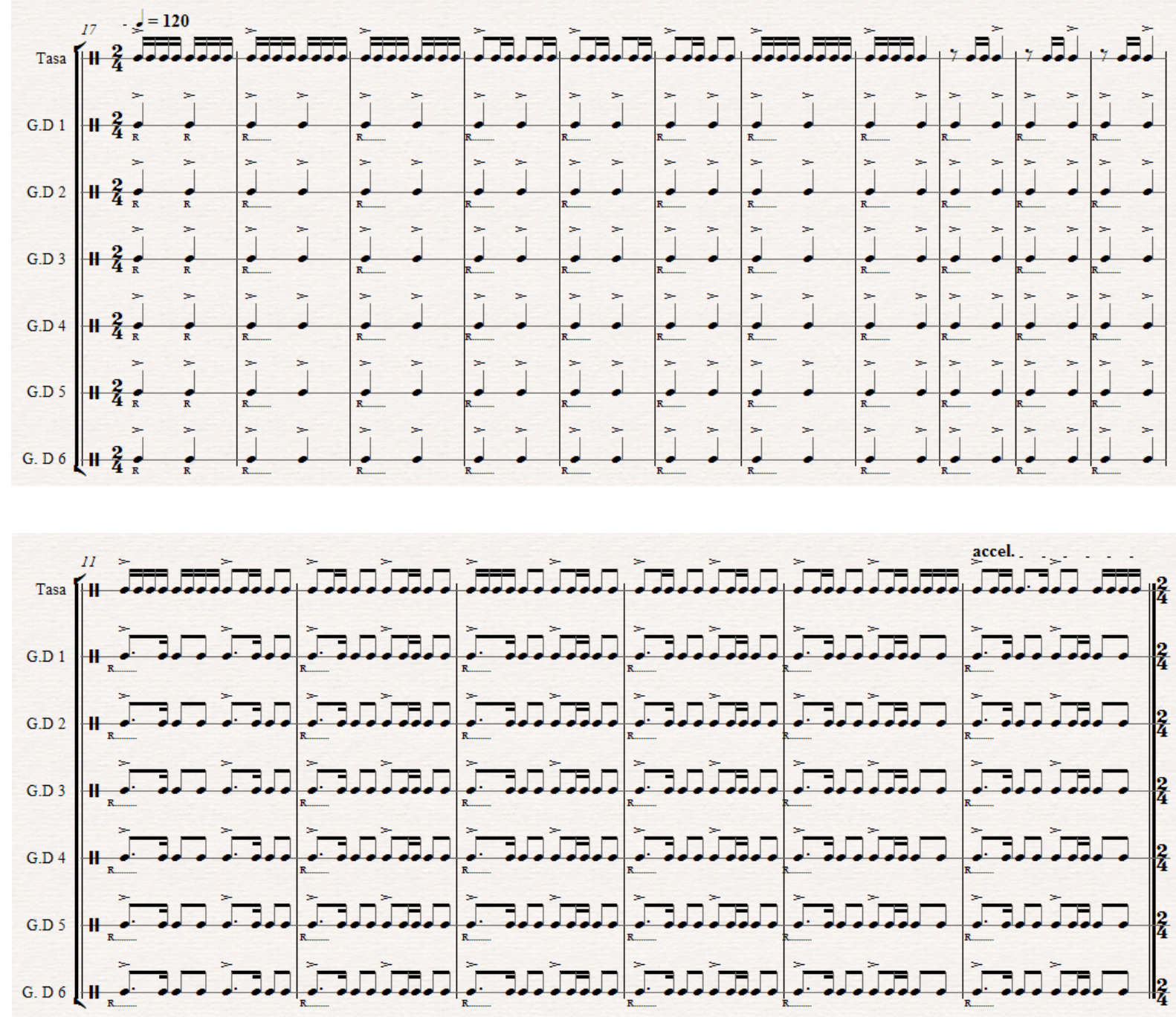
Humaniora, Vol. 27, No. 1 Februari 2015: 067-080
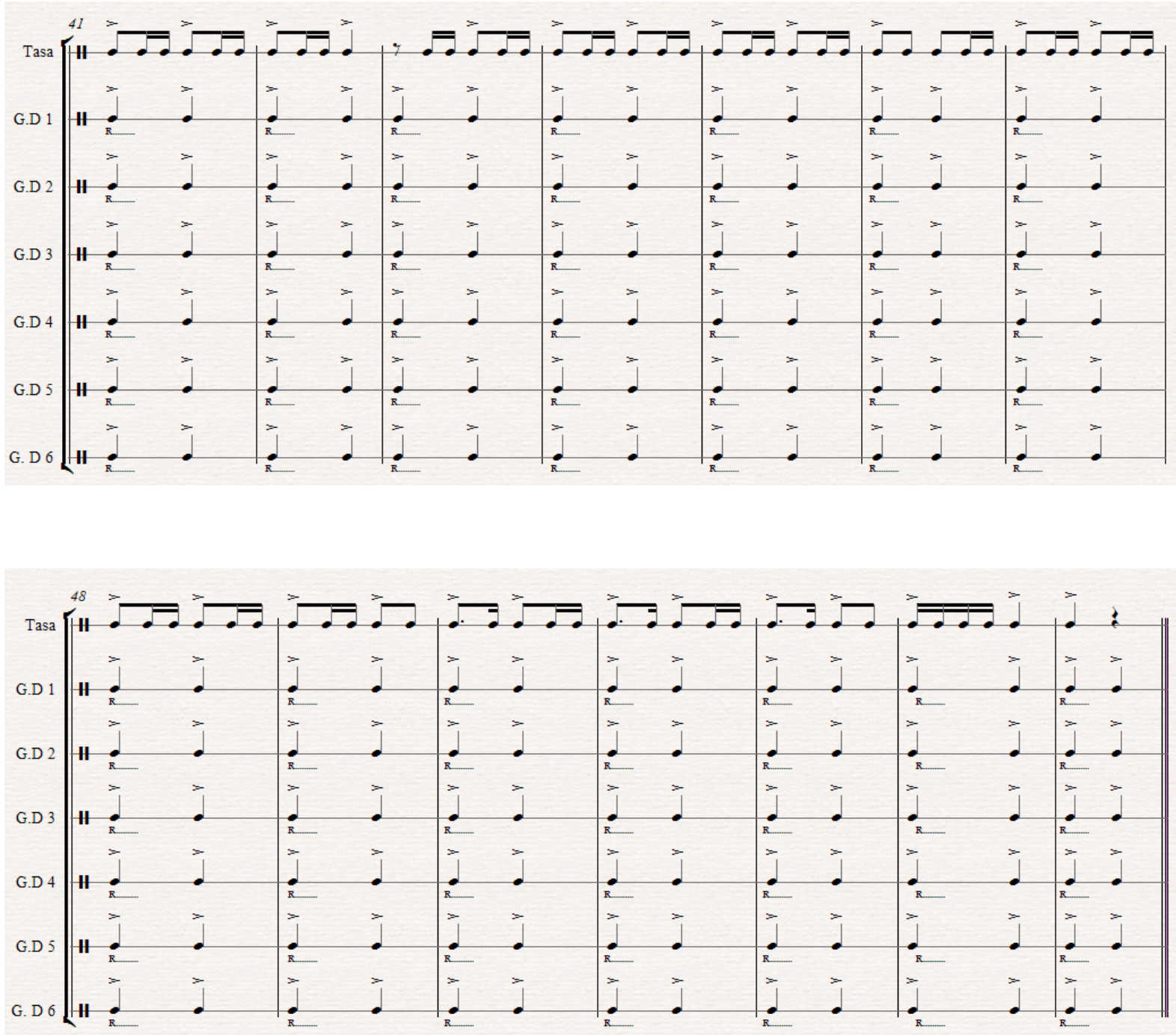